\title{
Inteligência Artificial (IA) e Arte
}

Philippe WILLEMART*

* Doutor em Letras - Língua e Literatura Francesa (1976) pela Universidade de São Paulo (USP). Professor Titular em Literatura Francesa da Universidade de São Paulo (USP). Contato: plmgwill@gmail.com.

\section{Resumo:}

Este ensaio tenta responder a uma pergunta: o robô poderia não somente imitar uma obra de arte, mas também inventar uma melodia à maneira de Chopin ou um conto à maneira de Flaubert, ou seja, com características da criação musical de Chopin e do estilo de Flaubert? $\mathrm{Na}$ primeira parte, percorrendo brevemente as várias tendências de pesquisas em inteligência artificial em diferentes partes do mundo: no Laboratório de pesquisa da Tecnologia e Criador do Spotify da Sony em Paris, no Departamento de musicologia da Universidade da Califórnia chefiado por David Cope, da Microsoft na França, da Universidade de Cambridge, na Microsoft Research da Ásia e no Departamento de pesquisa do Facebook dirigido por Yann Le Cun, levanto argumentos a favor e contra essa hipótese. Na segunda parte, aponto as dificuldades que teria um robô para imitar o estilo de um escritor devido à complexidade das palavras revelada pelos manuscritos, à sintaxe muitas vezes inovadora e à dificuldade de escuta da comunidade.

\section{Palavras-chave:}

Inteligência artificial. Le Cun. Crítica genética.

Signum: Estudos da Linguagem, Londrina, v. 23, n. 2, p. 10-22, ago. 2020 


\section{Inteligência Artificial (IA) e Arte}

Philippe Willemart

\section{INTRODUÇÃO}

A crítica literária ou artística e quem a pratica certamente já se viu confrontado com as invenções artísticas de um robô e pode se perguntar se é possível que uma máquina ultrapasse a mente humana. Lembremos com certo pavor e admiração a vitória da máquina Deep Blue da IBM sobre o campeão de xadrez Garry Kasparov, em 1997, e da máquina Watson da IBM sobre os dois campeões no jogo Jeopardy, em 2011, ou ainda da máquina Alpha Go da Google sobre o campeão Lee Sedol, no jogo de GO, mais difícil do que o xadrez, em 2016 (HARARI, 2016).

Para imitar o estilo de um autor, o sistema de inteligência artificial, chamado NLP (Natural Language Processing ou tratamento da linguagem natural $)^{1}$ faz uso de recursos de gramática e de sintaxe, identifica relações entre palavras, sonoridade etc. Aplicado às artes e à literatura, o princípio possibilitaria que um robô inventasse um conto à maneira de Flaubert, uma pintura à maneira de Rembrandt ou uma melodia à maneira de Bach?

Já foi tentado para Rembrandt, Bach e outros, mas o robô só pode iniciar sua invenção a partir da tela já pintada ou da melodia de Bach já composta. Trata-se de imitação e não de criação. Por isso, pergunto: será que o robô pode inventar um estilo, sem passar pela imitação (ROZIÈRES, 2017)? Pode capturar a riqueza da construção do manuscrito do escritor ou do compositor ou dos ensaios do pintor? Nada é menos certo!

\section{A Composição Musical}

O compositor e diretor do Laboratório de pesquisa da Tecnologia e Criador do Spotify, François Pachet (apud MANENTI, 2016), atesta a necessidade de um compositor no caso da criação musical:

Mesmo no modo automático, é uma criação, com um compositor que faz escolhas de estilo, produção, mixagem... Continua sendo o compromisso artístico de um autor. Não estamos tentando substituir músicos por autômatos [...]. Mas, todas essas tentativas sempre levam à mesma pergunta: a inteligência artificial pode competir criativamente com o homem? A máquina pode criar emoções com sua arte?

No entanto, David Cope, professor de musicologia da Universidade da Califórnia, relata uma experiência contrária. Ele criou o programa EMI (Experiments in Musical Intelligence) que consegue compor

\footnotetext{
${ }^{1}$ O PLN (NLP em inglês) é uma subárea da ciência da computação, da inteligência artificial e da linguística que estuda os problemas da geração e compreensão automática de línguas humanas naturais. Sistemas de geração de língua natural convertem informação de bancos de dados de computadores em linguagem compreensível ao ser humano e sistemas de compreensão de língua natural convertem ocorrências de linguagem humana em representações mais formais, mais facilmente manipuláveis por programas de computador. Dentre os desafios do PLN está a compreensão de uma língua natural, e fazer com que os computadores extraiam sentido da linguagem humana e a geração de língua natural.[...] O paradigma da aprendizagem automática induz a aprendizagem de regras por meio de análises de exemplos típicos do mundo real ao invés de usar algoritmos gerais de aprendizagem [...] No entanto, cada vez mais, a pesquisa tem se concentrado em modelos estatísticos, que tomam decisões flexíveis e probabilísticas baseadas em modos de agregar pesos reais a cada característica de entrada. Tais modelos têm a vantagem de poder expressar a certeza relativa de muitas respostas possíveis diferentes em vez de apenas uma, produzindo resultados mais confiáveis quando esse modelo é incluído como um componente de um sistema maior (WIKIPÉDIA).
} 
como Bach, Chopin, Rachmaninov, Stravinsky, ou seja, a máquina detecta e segue as regras de composição ou os algoritmos destes compositores, a ponto de os ouvintes confundirem Bach e EMI no decorrer de uma experiência de confronto na Universidade de Oregon. EMI segue três regras fundamentais: (1) desconstrução (analisar e separar em partes); (2) assinaturas (comunalidade - reter o que significa estilo); (3) compatibilidade (recombinância - recombinar em novas obras (COPE, 1982).

Auditores experimentados dizem ter sentido a mesma emoção ouvindo a composição original ou artificial (HARARI, 2016). A máquina é, portanto, capaz de despertar a emoção, mas imita o estilo do compositor. É o que confirma Bernard Ourghanlian (apud CHAILLOT, 2015), diretor técnico e de segurança da Microsoft na França:

O computador aprende com dados, por isso é baseado em trabalhos existentes. Mesmo que aprenda, é inspirado a uma reação. Ele é capaz de filmar conteúdo preditivo de forma inteligível, ele consegue gerenciar conteúdos em ambientes enormes e que excedem três dimensões, onde o ser humano se perde. Mas ele não inventa nada.

E se a máquina conseguir inventar um espetáculo, ele fica sem graça, escreve Manenti (2016):

De fevereiro a março de 2015, o musical 'Beyond the Fence' foi realizado em Londres, o primeiro criado inteiramente por uma máquina. Da música à letra e ao roteiro, tudo saiu de um computador da Universidade de Cambridge que peneirava centenas de peças de sucesso... para dar à luz a um show 'desbotado, inofensivo e agradável como uma bebida quente', de acordo com o jornal The Guardian.

Especialistas em música também rejeitam a invenção do programa informático Emily Howel derivado do EMI. Acusam a máquina de ter escolhido na obra de Chopin e de Mozart, por exemplo, trechos que embaralhou para apresentar sua invenção e de repetir muito os mesmos temas (COPE, 2012).

No entanto, o criador da EMI, também inventou a máquina ANNIE que não é mais baseada em regras pré-determinadas, mas compõe de acordo com os dados introduzidos do mundo exterior (HARARI, 2016; COPE, 2017). Em outras palavras, a máquina age como todos os compositores humanos, que também se inspiram das criações de seus antecessores (SZKLARZ, 2016).

A escuta dos autores do passado ou contemporâneos, que configura para o ser humano uma vasta memória musical e para o robô uma soma incalculável de algoritmos, produziria "o salto, o insight, o lance de dados genial que quebra um paradigma e instaura uma nova forma?” (BOSCO, 2017).

Diria que não, nem para o compositor, nem para o robô. Ainda que dê um salto genial, faltará ao robô uma dimensão vivida somente pelo ser humano, definida e comentada pelo narrador proustiano quando falava ao talento. Um texto será lido na medida em que tocará a "vida instintiva do público".

Para chegar à vida instintiva, o artista deve suprimir qualquer ruído externo e se colocar na escuta da vida, mas de uma maneira extremamente atenta como se escutasse um deus que fala. $\mathrm{O}$ instinto fala e anuncia e, tal um oráculo, exige a escuta. $\mathrm{O}$ talento consiste em ter a disposição necessária para, exercendo a pulsão do ouvir de uma maneira muito fina, perceber a mensagem. Não se trata, portanto, de estilo nem da oposição a uma escola anterior, mas de uma capacidade muito aguçada de entender uma mensagem lançada 'à la cantonade' que o escritor capta (WILLEMART, 2016, p. 41-42).

Ainda que o robô do Google possa deduzir aspirações e desejos de quem escreve mensagens, lê blogs e compra produtos por internet, mesmo que consiga reunir informações das demandas de vários internautas, nunca saberá captar a dimensão inconsciente ou não dita dos desejos de uma comunidade. O toque genial do artista, pelo contrário, que se deixa mover pela pulsão invocante, com sensibilidade sutil, irá escutar ou captar 
de algum modo os chamados da comunidade e poderá responder, mesmo sem reconhecer explicitamente a dimensão inconsciente.

\section{A Arte Literária}

A subsidiária asiática da Microsoft tem trabalhado para desenvolver e aperfeiçoar uma IA capaz de escrever poemas correspondentes a uma imagem apresentada a ela.

Os pesquisadores Bei Liu e Jianlong Fu da Microsoft Research da Ásia, juntamente com seus colegas, apresentaram os resultados de seus experimentos em torno da inteligência artificial, capaz de assumir o controle da criação poética automática, na conferência de 2018 da Association for Computing Machinery's Multimedia em Seul, na Coreia do Sul.

Simplificando, trata-se de gerar linguagem poética em resposta à informação apresentada na forma de uma imagem. O desafio é duplo: primeiro, a inteligência artificial deve ser capaz de "ver" a imagem. A pesquisa nessa área já está bem avançada, para que as máquinas possam descrever os elementos visuais e, assim, facilitar sua indexação e pesquisa.

Em seguida, a máquina deve atravessar uma lacuna: compor um texto que não seja descritivo ou somente descritivo, mas poético. Torná-lo poético a partir de uma sugestão de temas, a partir da prospecção desencadeada por uma imagem, é atividade complexa, mas viável para os recursos atuais das inteligências artificiais.

Diante dessas dificuldades, os pesquisadores permitiram que a máquina fizesse sua criação em verso livre, para evitar muitas restrições, como métricas e rimas. [...] É importante ressaltar que não definimos o que é poesia, disse Bei Liu. "Tentamos fazer com que a máquina aprendesse tanto poemas quanto textos não poéticos, para que pudéssemos distinguir se as frases geradas correspondiam ou não a um estilo poético", diz o pesquisador.

Os resultados são encorajadores, mas ainda longe do que um ser humano pode criar, é claro. Mas Bei Liu tem um texto favorito, correspondente à imagem:

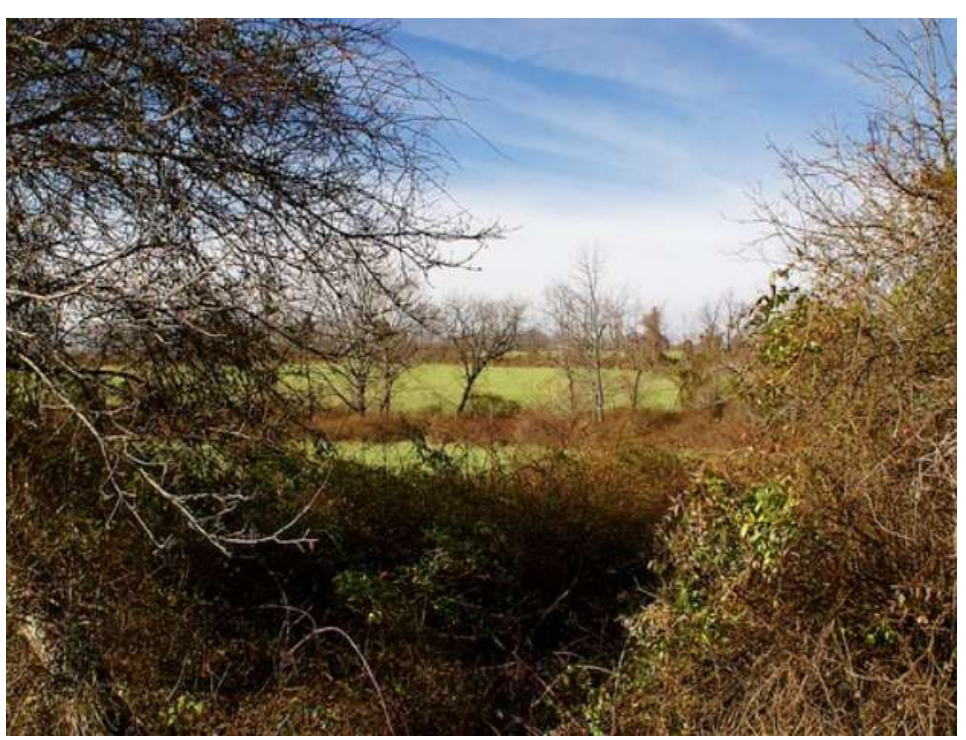

O sol está brilhando

$\mathrm{O}$ vento move árvores nuas

Você dança

O objetivo desta pesquisa não é substituir os poetas, esclarece a equipe, mas poder, a longo prazo, aproveitar as contribuições da inteligência artificial, e fazer com que a IA assuma o comando de tarefas redundantes de profissões criativas (OURY, 2018). 
Os criadores reconheceram a pobreza do poema, constatação que reforça o argumento do narrador proustiano. Até hoje, nenhum robô consegue criar obras musicais ou literárias na dimensão humana. Sem inconsciente nem pulsão invocante, o robô não consegue responder aos anseios da comunidade criando algo original. Grosso modo, trata-se da falta de subjetividade da máquina.

$\mathrm{Na}$ segunda parte do artigo, gostaria de reforçar o argumento proustiano interpretado à luz da teoria lacaniana e mostrar o que parece óbvio para a maioria dos geneticistas, o quanto é complexa a criação literária, e as dificuldades que encontraria a máquina, tomando como exemplo o conto Herodiade de Flaubert.

Três obstáculos para vencer:

\section{A) A complexidade das palavras}

Sem saber o que é o estilo de Flaubert, o robô poderia tentar apreender esse estilo de três maneiras: percorrendo o que deu origem aos manuscritos, seguindo passos do escritor, tais como leituras, viagens e demais experiências; lendo todos os manuscritos, tal como faz o crítico genético; ou se concentrando somente nos textos publicados do autor.

A.1 No primeiro caso, ele deveria ler a Bíblia e os livros sobre o Oriente consultados por Flaubert. Mas muitos livros são apenas acessíveis em bibliotecas até hoje e não constam na Nuvem (Cloud). O armazenamento de dados seria incompleto.

A.2 Se percorrer os manuscritos, o robô utilizará a aprendizagem da máquina, método chamado aprendizagem profunda. O engenheiro carregaria o robô com todas as informações numa primeira etapa. Numa segunda etapa, o robô traçaria as trajetórias entre o texto publicado e as informações acumuladas no manuscrito, tentando encontrar relações, segundo possibilidades da inteligência artificial, tais como similaridade das formas, e de modo muito mais limitado, relações do eixo semântico, e determinar, em seguida, o que os engenheiros, construtores de robôs, chamam de curva (LE CUN, 2019). A curva liga os pontos de chegada do aprendizado, isto é, as palavras ou as passagens que não mudarão mais durante a escritura, pontos que os estudiosos do manuscrito chamam invariantes. $\mathrm{O}$ aumento de invariantes será facilmente constatado nos fólios do início do conto de Flaubert nas figuras da página seguinte.

O conjunto dos pontos definirá o estilo do autor. A partir daí, a máquina trabalharia sozinha até conseguir deduzir um modelo ou articular regras para compor um conto à maneira de Flaubert seguindo os passos do ponto A.3. A dificuldade maior seria não somente determinar as frases subjacentes ou representadas no texto publicado, mas sobretudo a articulação com as variantes nos manuscritos. 


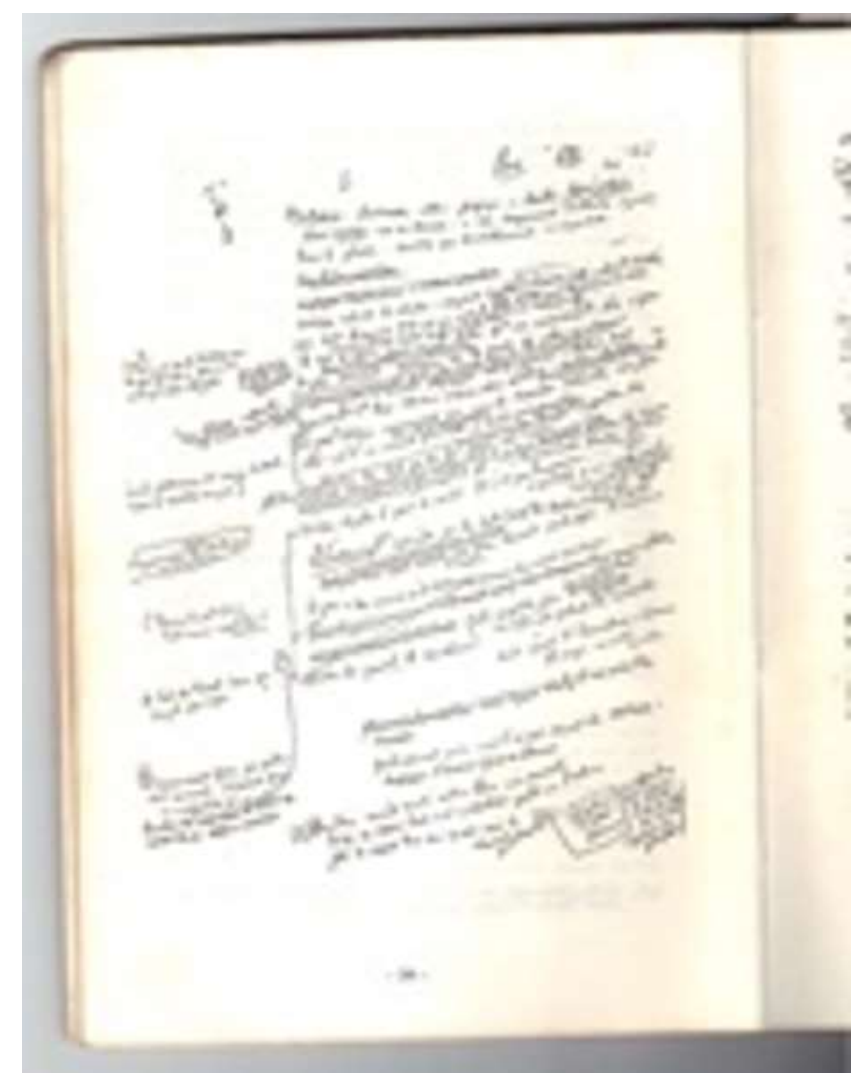

Fonte: Arquivos de pesquisa.

Imagem 1 - Fólio manuscrito do conto Hérodias, de Flaubert, parte 1

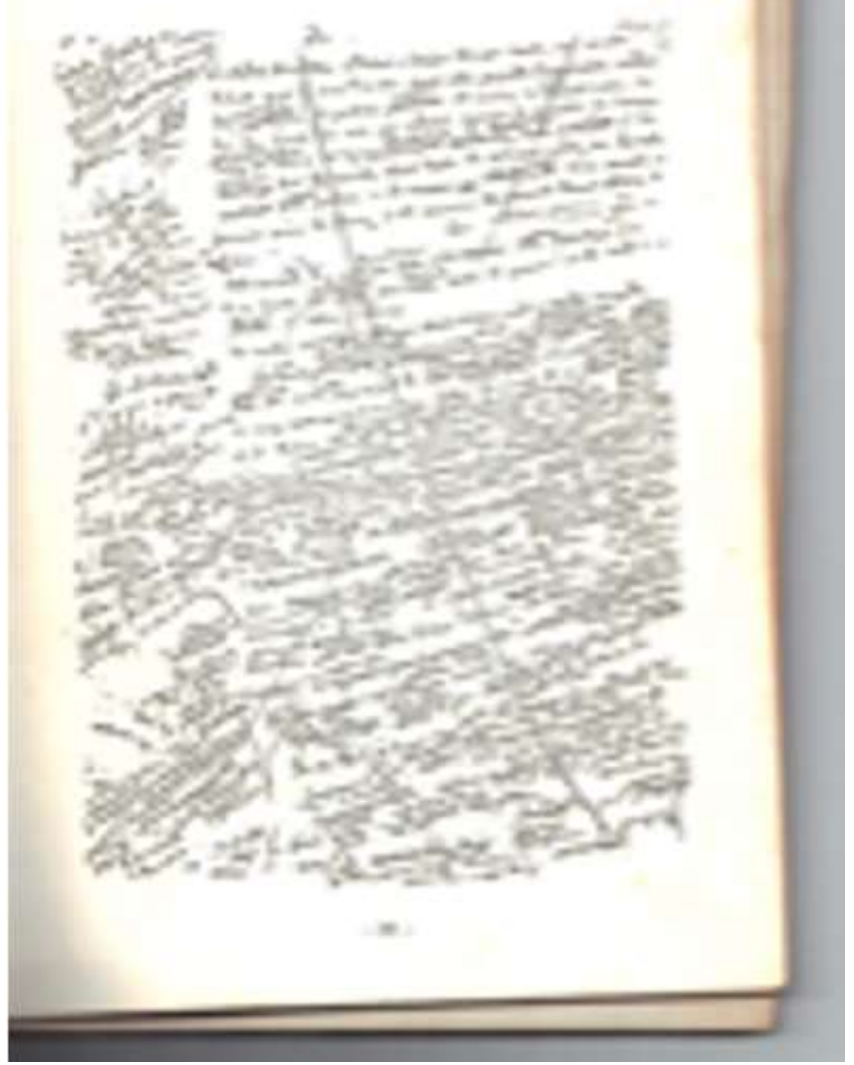

Fonte: Arquivos de pesquisa.

Imagem 2 - Fólio manuscrito do conto Hérodias, de Flaubert, parte 2 


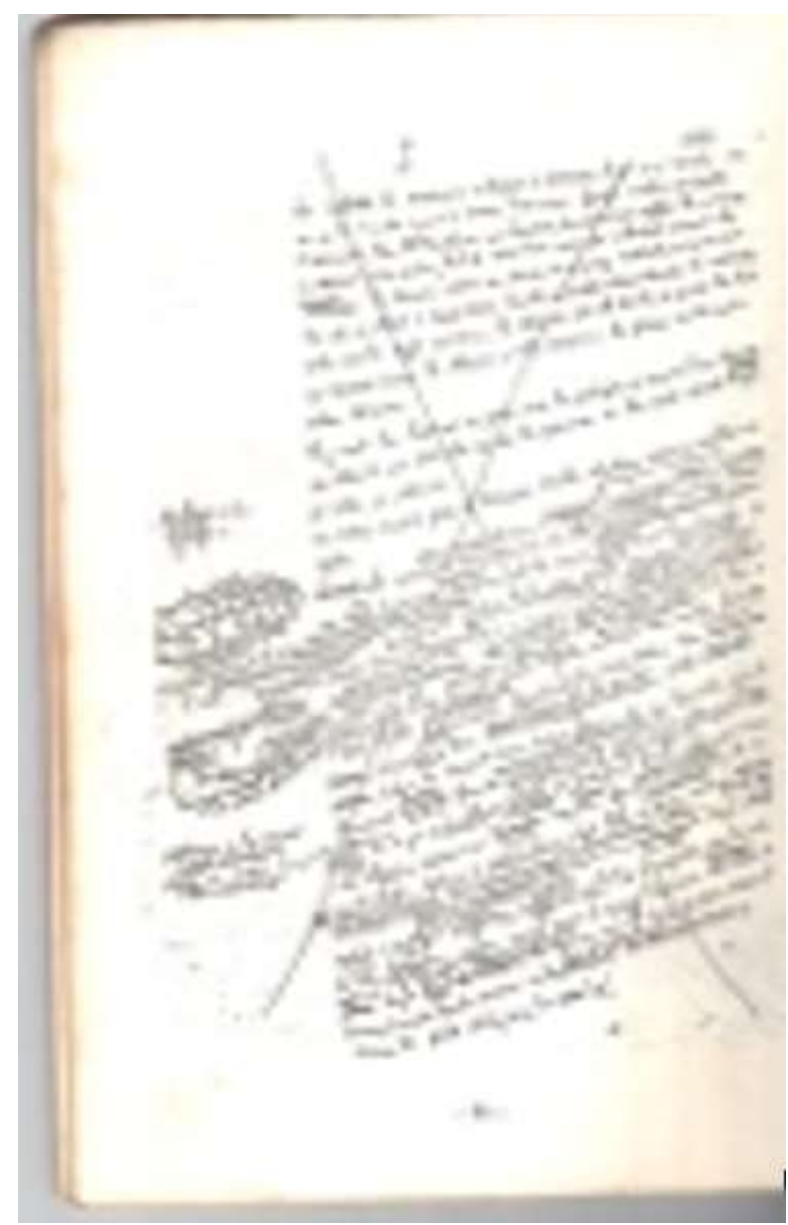

Fonte: Arquivos de pesquisa.

Imagem 3 - Fólio manuscrito do conto Hérodias, de Flaubert, parte 3

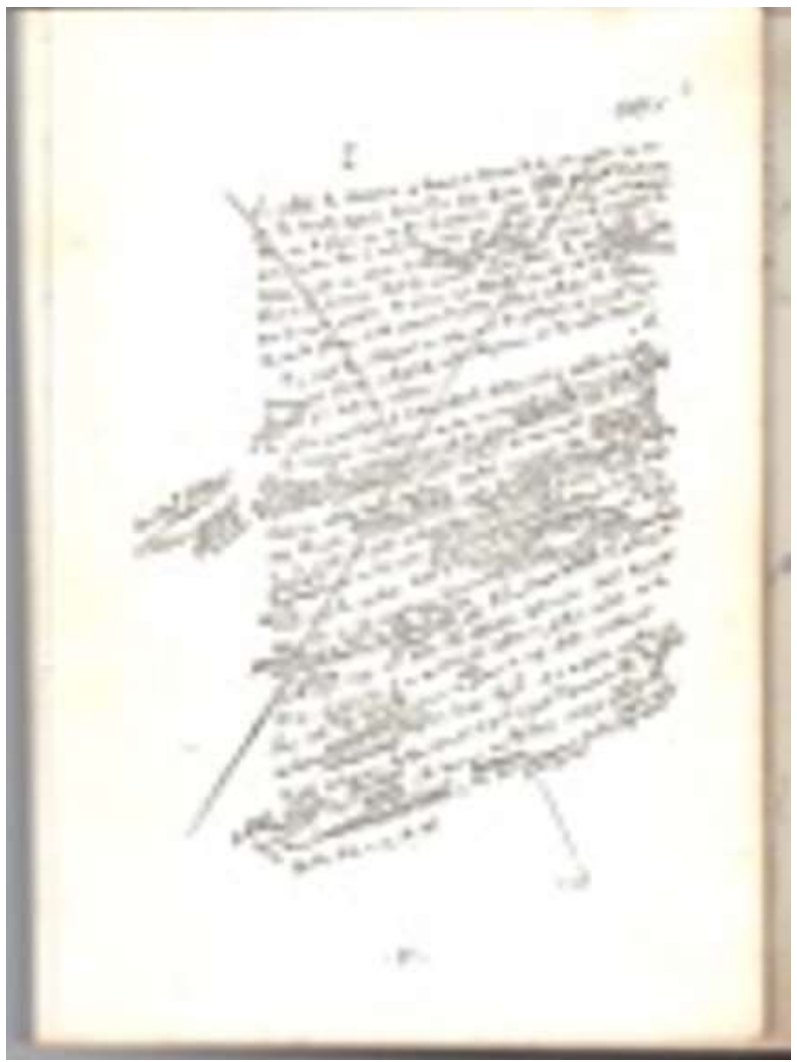

Fonte: Arquivos de pesquisa.

Imagem 4 - Fólio manuscrito do conto Hérodias, de Flaubert, parte 4 
A.3 Trabalhando somente com os dados do conto publicado e com a ajuda de "um extrator de características", que detecta apenas as formas, a máquina captaria as características essenciais do texto publicado ou seu estilo, que o diferencia de outros autores como Stendhal, Balzac ou Hugo -etapa complicada devido ao grande número de objetos ou palavras e à complexidade da sintaxe. Em seguida, armado do conjunto de qualidades do estilo de Flaubert, a máquina poderia não construir um algoritmo, mas deduzir os algoritmos de Flaubert, isto é, os passos que o autor Flaubert executou para chegar a seu estilo. Como algoritmo significa uma sequência finita de ações executáveis que visam obter uma solução para um determinado tipo de problema, o manuscrito do conto Hérodias seria de grande valia porque mostra as enormes dificuldades para redigir o conto. Mas ignorando o manuscrito, o robô seria capaz de encontrar os passos que levaram à última versão do conto?

Não se trata de entender a lógica que sustenta o texto, já que a máquina não raciocina, mas ajudado por seu imenso potencial de cálculos, ela definiria as múltiplas escolhas de Flaubert após cada frase, parágrafos e capítulos. Se considerar as palavras e expressões apenas como objetos, isto é, como unidade unívoca de sentido, a máquina agiria como o robô que reúne as características de uma faca que a distingue de uma colher. No entanto, aqui, não se trata somente de fabricar um objeto, mas de inventar um texto no qual cada palavra pode ter vários sentidos.

O texto publicado tem a vantagem sobre o manuscrito, cheio de dúvidas e hesitações, de ser constituído por uma série de conclusões lógicas articuladas e reconhecidas pelo autor. Bastaria teoricamente entender a lógica do texto publicado para imitar o estilo de Flaubert. O robô conseguiria reproduzir um texto parecido graças às camadas sucessivas que lhe permitem retroagir à medida que lê o texto e encontra os algoritmos do conto $?^{2}$

Isto é, à medida que avança na sua leitura, o robô deveria reler o que foi escrito após cada acréscimo e proceder da mesma maneira que age quando escrevo no iPad. Se escrever "jun", por exemplo, aparece imediatamente "junto" ou "Júnior”, se acrescento o “i”, "Juni”, aparece "Junina” ou "Júnior”. O robô Google que conhece todas as palavras que começa com jun, escolha algumas que uso normalmente. Se eu escrevo uma palavra inteira: "feliz", o Google lembra das mensagens anteriores e sugere "aniversário" seguido de "cara". Assim funciona o método das camadas sucessivas que retroagem para definir a palavra certa a partir de uma ou várias letras, primeiro passo para reconhecer ou sugerir uma palavra inteira. Imaginemos os cálculos exigidos para uma frase, um parágrafo ou um capítulo! Para imitar o estilo do conto, o robô deveria levantar o contexto de cada uma das 9580 palavras do conto. ${ }^{3}$

\footnotetext{
2 As técnicas de aprendizagem profunda (deep learning) constituem uma classe de algoritmos de aprendizagem de máquina, que possibilita: 1. Usar diferentes camadas de unidade de processamento não linear para extração e transformação de características; cada camada insere a anterior; algoritmos podem ser supervisionados ou não, e suas aplicações incluem reconhecimento de modelo e classificação estatística; 2. Trabalhar com aprendizado com múltiplos níveis de detalhes ou representação de dados; em diferentes camadas, passamos de parâmetros de baixo nível para parâmetros de nível superior, onde diferentes níveis correspondem a diferentes níveis de abstração de dados. Essas arquiteturas permitem que os dados sejam "significativos" dando-lhes a forma de imagens, sons ou textos. O aprendizado profundo usa camadas ocultas de redes neurais artificiais, as "máquinas Boltzmann restritas", e séries complexas de cálculos de propostas. Algoritmos de aprendizagem profunda se opõem a algoritmos de aprendizagem rasos devido ao número de transformações feitas nos dados entre a camada de entrada e a camada de saída, onde uma transformação corresponde a uma unidade de processamento definida por pesos e limiares (WIKIPEDIA). A maioria dos modelos modernos de deep learning são baseados em redes neurais artificiais, especificamente, redes neurais convolucionais $(\mathrm{CNN})$, embora também possam incluir fórmulas propostas ou variáveis latentes organizadas em camadas em modelos geradores profundos como os nós em redes de crenças profundas e máquinas Boltzmann profundas (WIKIPEDIA - tradução do francês por Google). A operação que calcula os milhões de neurônios números 1 que detectam as linhas verticais, é uma “convolução” (LE CUN, 2019).

${ }^{3}$ Rasurar consistirá para o escritor não em encontrar a curva certa ou a linha certa da história, que só existirá no final, mas em definir cada ponto, que nos rascunhos, oferecerá várias pistas. Passar por todos os pontos é o método, ou melhor, a arte do scriptor que saberá como ligá-los, muitas vezes na ignorância do escritor; quanto menos pontos deixados de fora, menos rasuras haverá, mais o estilo se afirmará. Quanto mais pontos não encontrados ou perdidos houver, mais rasuras e manuscritos haverá.
} 
Duvido que funcione, porque mesmo se o "polinômio ou a curva que liga os pontos de aprendizado esteja correta, o robô não entenderá o porquê. Ele seria parecido com um aluno que decora as tábulas de multiplicação sem entender como multiplicar” (LE CUN, 2019, p. 156).

\section{B) A sintaxe inovadora de Flaubert}

Supondo que a máquina mapeie as 9580 palavras do conto, ela não atingiria a sintaxe particular de Flaubert que define seu estilo. No decorrer da composição, o escritor procura continuamente o autor (ver a roda da escritura, WILLEMART, 2014) e consegue encontrá-lo inicialmente em algumas passagens e não em outras. Mme Bovary, seu primeiro romance, ainda tem frases que imitam o estilo de seus predecessores, segundo Proust (1971). Escrevendo, Flaubert constrói seu estilo gradualmente por meio da rede de personagens, das memórias anexadas aos episódios, dos fólios escritos sobre o assunto, usando uma sintaxe própria, último bastião da escritura, de acordo com Mallarmé. ${ }^{4}$

Como definir o estilo de Flaubert? Ou seja, quais são os algoritmos que o escritor forjou aos poucos e que o robô deveria encontrar? Respondendo a um crítico da época, que menosprezava o autor de Herodiade, Proust descreve o novo estilo de Flaubert não pela disposição das palavras no contexto e na frase, mas:

Pelo uso inteiramente novo e pessoal que ele fez do passado definido, do passado indefinido, de alguns pronomes e de certas preposições, renovou nossa visão das coisas quase tanto quanto Kant, com suas Categorias, as teorias do Conhecimento e da Realidade do mundo exterior (PROUST, 1971, p. 586).

Proust define assim vários dos algoritmos seguidos por Flaubert. Não vejo como um robô pode imitar a complexidade deste estilo salvo se, usando os mecanismos da máquina Annie de Pope, ele mistura algumas frases que usam o imperfeito e o perfeito, outras com preposições na sua narrativa. ${ }^{5}$

\section{C) A dificuldade da escuta}

Sabemos que o autor é antes de tudo, scriptor, a serviço da língua e das estruturas sociais das quais ele emerge e, sendo em parte "instrumento", ou seja, em posição de objeto, submisso à linguagem, ele não domina por completo sua escritura. Não há uma interpretação única e definitiva de um texto literário, cada um encontrará uma interpretação adequada com sua abordagem e com seu tempo. O robô não dará conta, portanto, de todas as camadas de interpretação do texto e, provavelmente, enxergará apenas a lógica incluída pelo seu inventor, o engenheiro, tanto quanto o fotógrafo "realiza algumas das virtualidades programadas" (FLUSSER, 1986, p.83) no seu aparelho de fotografia, e não o que ele queria. Dificilmente, a máquina contemplará o sentido poético, isto é, o sentido metafórico do texto. ${ }^{6}$ Dou vários exemplos.

A máquina não poderá relacionar "o guarda-sol com bolas", que aparece desde o plano, no folio 708 até o folio $722 \mathrm{v}^{\circ}$, emblema que definia a moeda cunhada sob Agrippa I - inimigo de Antipas apesar der ser irmão de Herodiade, mulher de Antipas - com o guarda-sol segurado por Salomé na primeira parte do conto publicado. O guarda-sol passaria desapercebido e considerado como um objeto qualquer nas mãos da filha de Herodiade e não simbolizaria o desejo de Antipas e de Herodiade de obter a realeza. A densidade do palavra "guarda-sol" sumiria numa narração linear e impediria o anúncio do advento de Calígula, como imperador, e

\footnotetext{
${ }^{4}$ Analisei uma frase do texto publicado que representa ou subentende uma série de sequências do manuscrito (WILLEMART, 1993).

${ }^{5}$ Um extrator de características detecta a presença de motivos distintivos na imagem de entrada e manda sua saída para um classificador treinado (LE CUN, 2019).

${ }^{6}$ As camadas sucessivas são uma versão treinada do extrator de características. É a vantagem decisiva das redes multicamadas: elas aprendem automaticamente a representar o sinal de maneira adequada (LE CUN, 2019).
} 
de seu amigo, Agrippa I, como rei de Jerusalém, assim como "o exílio para a Espanha do casal Antipas e Herodiade, onde terminaram a vida no mais profundo esquecimento" (BIASI, 1988, p. 747).

Numa narração linear robótica, sumiria também o efeito metafórico da última parte da frase do início do conto. A cidadela, que no folio $729 \mathrm{v}^{\circ}$ ocupava "a posição militar mais forte da Palestina", perde sua superioridade no texto publicado pois, "torres que estavam como florões nessa coroa de pedras suspensa acima do abismo" (FLAUBERT, 2019, p. 987) viram metáfora da realeza incerta de Antipas.

O robô poderia deduzir que a frase "Iaokanann, o mesmo a quem os Latinos chamam São João-Batista” (p. 1011) subentende a apresentação de João-Batista em quatro redações que mostram a síndrome da alucinação em Antipas e sua obsessão por Joao Baptista? Enquanto no folio 755, lemos:

Mas eles virão ? De repente, um ruído surdo e longínquo como uma voz saindo das profundezas da terra o faz estremecer. $<$ Empalidece $>$. vira-se, olha ,vai $<$ muito /ileg./ na frente do terraço - nada. É uma ilusão provavelmente ? <<retoma suas reflexões -pois tanto pensou que de repente, vê, lá diante dele em uma alucinaçãa um homem com pele de camelo, $<$ sob $>$ palmeiras a multidão na beira de um rio batizando uma multidão tem medo (WILLEMART, 1984, p. 56).

No texto publicado, sobraram apenas duas linhas: "De repente, uma voz distante, como que saindo das profundezas da terra, fez o tetrarca empalidecer. Ele se inclinou para ouvir, havia cessado" (FLAUBERT, 2019, p. 1003).

A palavra "alucinação" sumiu. Qualificar Antipas de uma certa estranheza dando-lhe alucinações, evocaria as novas distinções da ciência médico-psicológica do final do século XIX, pouco congruentes com o mundo da Antiguidade. Talvez por isso Flaubert teria preferido atribuir-lhe visões nas quais Antipas parece perdido no final do primeiro capítulo (WILLEMART, 1993), mas o robô não suspeitaria dessa densidade da palavra "visão" que liga o primeiro século às descobertas científicas do tempo de Flaubert.7

Última ressalva: o relatório do Senado francês de novembro de 2019 (Anexo 1) sobre as limitações da Inteligência artificial reforça as dificuldades de um robô para compor uma melodia, um conto ou uma poesia.

\section{Considerações FinaIs}

Ao longo do artigo, percorri brevemente as várias tendências de pesquisas em inteligência artificial em diferentes partes do mundo: no Laboratório de Pesquisa da Tecnologia e Criador do Spotify da Sony em Paris, no Departamento de musicologia da Universidade da Califórnia, chefiado por David Cope, na Microsoft na França, na Universidade de Cambridge, na Microsoft Research, e no Departamento de Pesquisa do Facebook, dirigido por Yann Le Cun.

\footnotetext{
7 O tempo da História alcançado pela ficção relê a narração de um outro modo e convida o leitor a negativizar a pretensão de Herodías, presa na sua própria armadilha. Cada aparição de Salomé, marcada pelo olhar do tetrarca, simboliza a perda do poder do casal que ambiciona a realeza. A dança e a promessa louca de Antipas indicam o fim das ambições daquela que queria igualar a grande Mariana. O poder dificilmente tolera a dependência de um gozo. É uma lição conhecida e comum da História, retomada através da intriga de Herodías e de Iaokanann. As borlas disseminadas no manuscrito sob o guarda-sol de Salomé tocam o dobre de finados de uma esperança vã. A repetição marcada do significante Salomé a cada capítulo insiste na negação daquilo que acaba de ser escrito e repõe o leitor, sem o seu conhecimento, na realidade futura. João-Batista também tinha profetizado, do fundo de seu fosso, a decaída de Herodías e de Antipas: "O castigo já baixou sobre teu incesto. Deus te castiga com a esterilidade das mulas. /.../ (e para Herodías) O Senhor arrancará teus brincos, teus vestidos de púrpura, teus véus de linho" etc., mas esse discurso era religioso e não político como o anúncio do reino de Agrippa. O escritor Flaubert, que repete, aparentemente, o discurso religioso da Bíblia deixa passar um discurso "leigo", o do ocupante (WILLEMART, 1993).
} 
A partir dos dados coletados, levantei argumentos favoráveis e contrários à hipótese de que um robô poderia imitar uma obra de arte com características de criação próprias do artista. Em um segundo momento, apontei as dificuldades que teria um robô para imitar o estilo de um escritor devido à complexidade das palavras revelada pelos manuscritos, à sintaxe muitas vezes inovadora e à dificuldade de escuta da comunidade.

Concluo que, até o momento, nenhum robô consegue criar obras musicais ou literárias na dimensão humana. Sem inconsciente nem pulsão invocante, o robô não alcança a complexidade subjetiva da criação nem consegue responder aos anseios da comunidade. Assim, espero ter convencido meu leitor que um robô tem poucas chances de igualar qualquer escritor, apesar de seu potencial imenso de cálculos e de seu poder de memória.

\section{ANEXo $1^{8}$}

Senado da França. Amanhã robôs: rumo a uma transformação de empregos de serviço.

Relatório de Informações 162 (2019-2020) de Marie MERCIER e René-Paul SAVARY, feito em nome da Delegação do Senado para a Previsão, apresentado em 28 de novembro de 2019.

Marie Mercier, relatora. O que é inteligência? Nós definimos isso como uma habilidade de raciocínio. No entanto, a IA é capaz de fazer cálculos muito rapidamente, mas não raciocinar por seu próprio raciocínio. A IA não fará zero falhas e não poderá ver seus limites, mas reserva surpresas. Pensamos há 30 anos que robôs substituiriam cirurgiões. Esse não é o caso hoje. Paradoxalmente, os especialistas médicos estão mais ameaçados do que os clínicos gerais pela intrusão da IA na saúde. O trabalho que realizamos na Delegação de Previsão tem como objetivo examinar o impacto da IA no trabalho de serviço. Robôs de recepção substituirão os trabalhadores de recepção? Ou vamos avançar para o trabalho colaborativo entre homens e máquinas?

Mrs. Christine Lavarde. - Vemos hoje que o crescimento francês está atingindo seu máximo porque estamos na capacidade máxima de mobilizar nosso aparato produtivo: parece que as pessoas empregadas hoje simplesmente não podem sê-lo. No entanto, será preciso grandes habilidades para explorar o aprendizado profundo (Deep learning) porque temos que entender uma IA mais forte do que nós. Isso é possível?

Mr. Laurent Alexandre. - É de se temer que não. As lacunas explodirão porque os potenciais de cada um são muito diferentes. Um estudo que avaliou o programa "Nenhuma criança deixada para trás" dos EUA mostrou uma redução das lacunas educacionais quando foram feitos investimentos específicos para os mais desfavorecidos, mas provou ser falso e os responsáveis por este estudo foram processados pelos tribunais. A duplicação dos CPs não dá bons resultados porque é muito marginal. A IA pode substituir pessoas qualificadas, mas consome cada vez mais cérebros. Cérebros são escassos. Vamos ter uma escassez de trabalhadores inteligentes em 20 anos. A IA não substitui o cérebro, mas complementa a inteligência humana. O pesquisador Serge Abiteboul nos diz que "ser um cientista de dados requer muitos cérebros disponíveis".

Mr. Laurent Alexandre. - Nas minhas palestras, muitas vezes me perguntam o que ensinar às crianças. Eu respondo: humanidades, história, filosofia, cultura geral. Aprender a codificar é inútil.

Sr. Axel Dyèvre, Diretor Associado do CEIS. A palavra "inteligência" no termo "inteligência artificial" é um abuso da linguagem, uma expressão sedutora para buscar créditos de pesquisa na década de 1950. Luc Julia, o inventor da assistente de voz Siri afirmou em um livro que a inteligência artificial não existia. Quando se trata de defesa, as linhas de uso da IA diferem de país para país. Os americanos usam a IA para aumentar as habilidades do soldado com uma doutrina ofensiva. Os chineses estão tentando aumentar seu sistema de

${ }^{8}$ Disponível em: https://bit.ly/3rWSVBH. 
armas em uma lógica de proibição defensiva. Os russos usam a IA como multiplicador de força. Os israelenses usam a IA para acelerar o tempo de reação. A IA é um multiplicador das capacidades da inteligência humana, mas não um substituto para ela. Não devemos ser enganados por avanços de software. São as capacidades computacionais, as máquinas, o hardware, que permitiram que o software registrasse um desempenho importante. A IA tornou-se muito eficiente, mas também tem suas próprias limitações: o computador não pode antecipar o imprevisível.

Sr. Jean-François Mayet. - Não são os países mais robóticos que têm mais desemprego. A inteligência das máquinas não é uma inteligência social: baseia-se apenas na capacidade de armazenar e processar rapidamente enormes quantidades de informações. Robôs também têm grande força: eles não se enganam ...

\section{ANExo 2}

Que um computador, Deep Blue, foi capaz de vencer Gary Kasparov no xadrez em 1997 foi a apoteose e o fim das ambições deste programa de pesquisa. A inteligência artificial fracassou contra a infinita diversidade de contextos. Tornar a máquina "inteligente" é inútil se não souber adaptar seu raciocínio a cada situação. Ora, a maioria das situações da vida real não são "codificadas", assim como as regras para mover as peças do xadrez (Caron, 2015).

\section{REFERÊNCIAS}

APRENDIZAGEM PROFUNDA. In: WIKIPEDIA, a enciclopédia livre. Disponível em: http://bit.ly/3qjTBRq. Acesso em: 03 jun. 2020.

BIASI, P-M. Carnets de travail de Gustave Flaubert. Paris: Balland, 1988.

BOSCO, F. A segunda morte do autor. Revista Cult, 10 mar. 2017. Disponível em: http://bit.ly/3jHtTDH. Acesso em: 08 jun. 2020.

CARON, D. A quoi rêvent les algorithnes. Paris: Seuil, 2015.

CHAILLOT, M. Et si votre prochain morceau préféré était chanté par une intelligence artificielle ? Neon, 4 dez. 2015. Disponível em: https://bit.ly/3p9W7bj. Acesso em: 08 jun. 2020

COPE, D. Experiments in musical intelligence. 1982. Disponível em: https://bit.ly/3tMRVSl. Acesso em: 09 jun. 2020.

COPE, D. Chopin style nocturne Emmy. 22 out. 2012. (2m23s). Disponível em: https://bit.ly/3dh3sUr. Acesso em: 10 jun. 2020.

COPE, D. Mozart style sonata. 25 out. 2017. (4m04s). Disponível em: https://bit.ly/3d3Xq9x. Acesso em: 10 jun. 2020.

FLAUBERT, G. Os três contos. Tradução Júlia da Rosa Simões. São Paulo: L\&PM, 2019.

FLUSSER, V. Filosofia da caixa preta. São Paulo: É Realizações, 1983. 
HARARI, Y. N. Homo Deus. Tradução Paulo Geiger. São Paulo: Companhia das Letras, 2016.

LE CUN, Y. Quand la machine apprend. Paris: Odile Jacob, 2019.

MANENTI, B. Musique: demain, ce sont les robots qui créeront les tubes. L'OBS, 27 set. 2016. Culture. Disponível em: bit.ly/3aVvNgb. Acesso em: 10 jun. 2020.

OURY, A. Ce robot-Rimbaud écrit des poèmes, inspiré par une image. ActuaLitté, 26 out. 2018. Disponível em: http://bit.ly/3d4mOvR. Acesso em: 09 jun. 2020.

PROCESSAMENTO DE LINGUAGEM NATURAL. In: WIKIPEDIA, a enciclopédia livre. Disponível em: http://bit.ly/3rLdmBG. Acesso em: 03 jun. 2020

PROUST, M. À propos du "style " de Flaubert. 1o de janeiro de 1920. Contre Sainte-Beuve. Paris: Gallimard, 1971.

ROZIÈRES, G. Une intelligence artificielle a créé 20 albums de musique pour Warner Music. Huffpost, 25 mar. 2019. Disponível em: http://bit.ly/3qgW12U. Acesso em: 05 maio 2020.

SZKLARZ, E. Um computador sentimental como Mozart. SuperInteressante, 26 ago. 2010 (atual. 31 out. 2016). Tecnologia. Disponível em: http://bit.ly/3tR31WE. Acesso em: 05 jun. 2020.

WILLEMART, P. O manuscrito em Gustave Flaubert. São Paulo: FFLCH, 1984. Disponível em: http://bit.ly/2Zk1ESg. Acesso em: 09 jun. 2019.

WILLEMART, P. Universo da criação literária. São Paulo: Edusp, 1993.

WILLEMART, P. Psicanálise e teoria literária. São Paulo: Perspectiva, 2014.

WILLEMART, P. Os processos de criação em 'À sombra das raparigas em flor'. Cotia: Ateliê, 2016. 